\title{
Poincaré plots to analyze photoplethysmography signal between non-smokers and smokers
}

\author{
Bagus Haryadi', ${ }^{1,2}$ Po-Hao Chang ${ }^{1}$, Akrom $^{3}$, Arifan Q. Raharjo ${ }^{2}$, Galih Prakoso² \\ ${ }^{1}$ Department of Electrical and Engineering, National Dong Hwa University, Hualien County, Taiwan \\ ${ }^{2}$ Department of Physics, Universitas Ahmad Dahlan, Yogyakarta, Indonesia \\ ${ }^{3}$ Department of Pharmacology and Clinical Pharmacy, Universitas Ahmad Dahlan, Yogyakarta, Indonesia
}

\begin{tabular}{l}
\hline \hline Article Info \\
\hline Article history: \\
Received Apr 1, 2021 \\
Revised Oct 14, 2021 \\
Accepted Nov 2, 2021 \\
\hline
\end{tabular}

Keywords:

Blood circulation

Photoplethysmography signal

Poincaré plots

Smokers

\begin{abstract}
An analysis of blood circulation was used to identify variations of heart rate and to create an early warning system of autonomic dysfunction. The Poincaré plot analyzed blood circulation using photoplethysmography (PPG) signals between non-smokers and smokers in three different indices: SD1, SD2, and SD1 SD2 ratio (SSR). There were twenty subjects separated into non-smoker and smoker groups with sample sizes of 10, respectively. An independent sample t-test to compare the continuous variables. Whereas, the comparison between two groups employed Fisher's exact test for categorical variables. The result showed that SD1 was found to be considerably lower in the group of smokers $(0.03 \pm 0.01)$ than that of the non-smokers $(0.06 \pm 0.03)$. Similarly, SSR was recorded at $0.0012 \pm 0.0005$ and $0.0023 \pm 0.0012$ for smoking and non-smoking subjects, respectively. As a comparison, SD2 for non-smokers $(25.7 \pm 0.5)$ was lower than smokers (27.3 \pm 0.4$)$. In conclusion, we revealed that the parameters of Poincaré plots (SD1, SD2, and SSR) exert good performances to significantly differentiate the PPG signals of the group of non-smokers from those of smokers. We also supposed that the method promises to be a suitable method to distinguish the cardiovascular disease group. Therefore, this method can be applied as a part of early detection system of cardiovascular diseases.
\end{abstract}

This is an open access article under the CC BY-SA license.

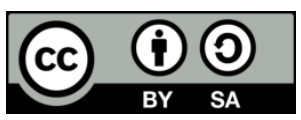

\section{Corresponding Author:}

Bagus Haryadi

Department of Physics, Universitas Ahmad Dahlan

Jendral A. Yani street, Tamanan, Banguntapan, Bantul, Daerah Istimewa Yogyakarta, Indonesia

Email: bagus.haryadi@fisika.uad.ac.id

\section{INTRODUCTION}

Photoplethysmography (PPG) is one of the medical devices that possesses many advantages such as low-cost, high-reliability, and easy to use. The application of PPG in the public health center can help paramedics to treat patients easier. A low-priced PPG reduces healthcare service costs as well. In other that, the PPG signal is suitable to assess some of cardiovascular diseases (CVDs) such as diabetes [1]-[3], hypertension [4]-[6], erectile dysfunction [7], atherosclerosis [8], coronary artery disease [9], [10] and coronary heart disease [11]. It is also convenient for clinical application, for example, in the measurement and monitoring of heart rate [12]-[14] and blood pressure [15], [16]. CVDs as the most critical and the most significant contribution of death almost around the world recently are associated with smoking as well [17], [18]. Smoking is related to parasympathetic withdrawal and sympathetic augmentation in nerve activities [19]. Cigarette contains tobacco nicotine as a sympathomimetic agent. As a sympathomimetic agent, nicotine stimulates adrenaline secretion. Adrenaline stimulates the work of the heart and vasoconstriction of blood vessels. In addition to nicotine, cigarette also contains carcinogenic compounds that are harmful to endothelium 
homeostasis of blood vessels. Disruption of endothelial homeostasis causes the impaired function of nitric oxide synthase (NOS) so that the production of nitric oxide (NO) compounds, which play an essential role in regulating blood flow, is reduced [20].

Blood regulation is associated with the peak to peak fluctuation in PPG or pulse rate variability (PRV). The PRV reveals the autonomic nervous system (ANS) time-varying [21]. The ANS is one of the components involved in regulating NO secretion. A decrease in plasma NO levels causes an increase in sympathetic nerve activity [22]. PRV derived from the PPG pulse amplitude signal is compatible with heart rate variability from electrocardiogram (ECG) and blood pressure [23]. Changes in heart rate variability (HRV) correspond to changes in PRV in both physiological and pathological conditions [24]. In healthy subjects, PRV is in line with HRV [25] both in an awake condition and a sleep state [26]. PRV contains the non-linear signal that can be analyzed by the Poincaré plot. The aim of this study is the investigation of the Poincaré plot application to analyze of blood circulation using photoplethysmography signals between non-smoking and smoking subjects. Therefore, this method can be applied as a part of early detection system of CVDs.

\section{RESEARCH METHOD}

\subsection{The system of a low-cost PPG}

The hardware system consists of Arduino Uno which has a low power and highly efficient microcontroller based on AT Mega 328 and other electronic components such as resistor, capacitor, and integrated circuit (IC), while the software consists of the Arduino integrated development environment (IDE) and LabVIEW. The hardware system also includes units such as the IR sensor, the $2^{\text {nd }}$-order high pass filter (HPF), the instrumentation amplifier (Ins-Amp), the $2^{\text {nd }}$-order low pass filter (LPF), and Arduino Uno. LabVIEW was employed to visualize and store data. The diagram of system is shown in Figure 1.

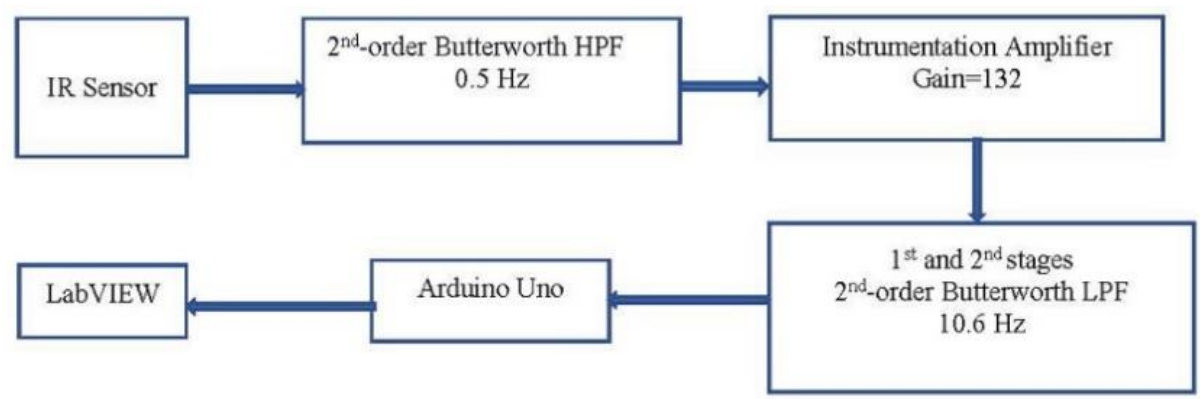

Figure 1. The diagram of a low-cost PPG system

\subsection{Data acquisition}

The PPG signals are recorded by using a low-cost PPG based on Arduino created by us. Furthermore, the signals were edited to get the peak to peak time (PPT). The PPT is determined by using custom software in MATLAB to analyze PRV features. Data acquisition is conducted for one minute with a sampling rate of $155 \mathrm{~Hz}$. The recorded data were then digitized with 10-bit resolution and stored in a personal computer using LabView for further analysis. The signal analysis of Poincaré indices is computed by using MATLAB 2016 b (The Mathwork Inc.).

\subsection{Study protocol}

Twenty people, all males, are separated into two groups, namely the non-smokers and smokers, with a sample size of ten, respectively. Subjects, aged 18-35 years (average age of 25.0 \pm 4.2 ) were volunteers who were declared clinically healthy by doctors in primary health care. Smoker's criteria were subjects who had smoked at least one stick cigarettes/day during the past five years. On the other hand, the criteria for nonsmokers are those subjects who had not smoked cigarettes in the past five years. Voluntary non-smokers and smokers are recruited from two villages in Yogyakarta, Indonesia, and from students at the Universitas Ahmad Dahlan, Yogyakarta in September 2019. Before the data acquisition, all subjects were asked to not consuming food and beverages at least for 8 hours. During the study, volunteers received health education about the dangers and adverse effects of smoking. The Health Research Ethics Committee of the Faculty of Medicine and Health Sciences, University of Muhammadiyah Yogyakarta had responsibility to approve this study (number:166/EP-FKIK_UMY/V/2019). 


\subsection{Poincaré plot analysis}

PRV derived from PPG pulse amplitude signal can be analyzed by Poincaré method. The conservative 2D Poincaré plot; i.e., the first delayed Poincaré plot, can be produced by plotting each PPT of PPG as a function of its previous PPT ([PPT(n), PPT $(n+1])$. The time from the fixed sequence of PPT in (1) is selected, and then the set of the first delay on the time of PPT (2) is defined as follows:

$$
\begin{aligned}
\text { PPT }^{\prime} & =\{\operatorname{PPT}(1), \operatorname{PPT}(2), \ldots, \operatorname{PPT}(n-1)\} \\
\text { PPT }^{\prime \prime} & =\{\operatorname{PPT}(2), \operatorname{PPT}(3), \ldots, \operatorname{PPT}(n)\}
\end{aligned}
$$

There are three indices of the results: the standard deviation (SD) of the short term of PPT or SD1 in (3), the SD of the long term of PPT or SD2 in (4), and SSR in (5).

$$
\begin{aligned}
& \mathrm{SD} 1=\sqrt{\operatorname{var}\left(\mathrm{PPT}^{\prime}-\mathrm{PPT}^{\prime \prime}\right) / \sqrt{2}} \\
& \mathrm{SD} 2=\sqrt{\operatorname{var}\left(\mathrm{PPT}^{\prime}+\mathrm{PPT}^{\prime \prime}\right) / \sqrt{2}} \\
& \mathrm{SSR}=\mathrm{SD} 1 / \mathrm{SD} 2
\end{aligned}
$$

\subsection{Statistical analysis}

The distribution of the data was normal. The data expressed as mean \pm standard deviation (SD). The statistical analysis applied SPSS ver. 22 to determine whether there are differences between the groups of nonsmokers and smokers when more than one PRV feature is obtained. We used independent sample t-test to contrast the continuous variables. Whereas, comparison between two groups employed fisher's exact test for categorical variables. $\mathrm{P}<0.05$ is considered statistically significant. The PRV features (SD1, SD2, and SSR) are the dependent variables.

\section{RESULTS AND DISCUSSION}

\subsection{Features of non-smoking and smoking subjects}

Table 1 shows the characteristics of subjects either non-smoking or smoking subjects. All subjects are male to show there is no gender difference in this study. The non-smoking and smoking subjects also similar in their age (24.0 \pm 2.8 and $25.9 \pm 5.2)$. The non-smokers showed remarkably lower blood glucose levels than those in the smoker subjects $(\mathrm{p}<0.05)$. On the contrary, others demographic parameters (height, weight, body mass index (BMI)) and hemodynamic parameters (systolic blood pressure (SBP), diastolic blood pressure (DBP), heart rate) were similar between the two groups.

Table 1. Features of non-smoking and smoking subjects

\begin{tabular}{cccc}
\hline Parameters & $\begin{array}{c}\text { Non-smoker } \\
\mathrm{n}=10\end{array}$ & $\begin{array}{c}\text { Smoker } \\
\mathrm{n}=10\end{array}$ & $\mathrm{p}$-value \\
\hline Male, $\%$ & 100 & 100 & 1.000 \\
Age, year & $24.0 \pm 2.8$ & $25.9 \pm 5.2$ & 0.327 \\
Height, $\mathrm{m}$ & $1.70 \pm 0.04$ & $1.68 \pm 0.06$ & 0.437 \\
Weight, $\mathrm{kg}$ & $67.9 . \pm 19.5$ & $65.5 . \pm 11.7$ & 0.741 \\
BMI, $\mathrm{kg} / \mathrm{m}^{2}$ & $23.5 \pm 6.9$ & $23.0 \pm 4.3$ & 0.866 \\
SBP, $\mathrm{mmHg}$ & $118.8 \pm 12.5$ & $128.5 \pm 11.5$ & 0.088 \\
DBP, $\mathrm{mmHg}$ & $84.4 \pm 9.1$ & $82.0 \pm 9.2$ & 0.565 \\
Heart Rate, $\mathrm{mmHg}$ & $84.3 \pm 9.1$ & $79.8 \pm 10.5$ & 0.484 \\
Blood Glucose, $\mathrm{mg} / \mathrm{dL}$ & $83.8 \pm 31.6$ & $166.1 \pm 99.9$ & 0.040 \\
\hline
\end{tabular}

\subsection{Comparison of Poincaré plots between non-smoker and smoker}

The comparison of raw PPG signal and Poincaré plot displays in Figure 2. The Figure 2(a) is a raw PPG signal of a non-smoker, while the Figure 2(b) is Poincaré plot of PPG signal from a non-smoker. Otherwise, Figure 2(c) shows a raw PPG signal of a smoker and Figure 2(d) presents Poincaré plot of PPG signal from a smoker. The PPG signal amplitude of non-smoker is higher than smoker (left side). It confirms that the blood circulation of non-smoker is more smoothly than smoker. The distinction of non-smoker and smoker also can be seen from the Poincaré plot section (right side). It shown that the short-term variation of 
PPG signal of non-smoker is wider than smoker relating to blood moving in the arteries. On the other hand, the long-term variation of PPG signal of non-smoker is slighter than smoker.

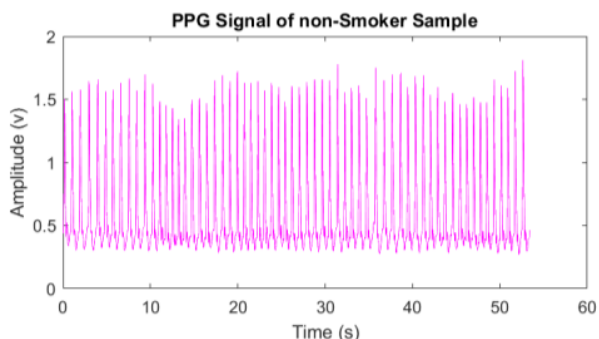

(a)

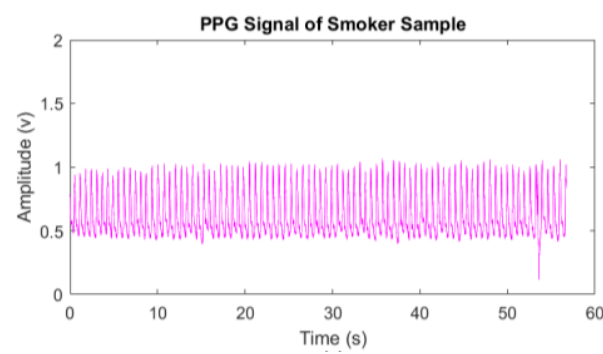

(c)

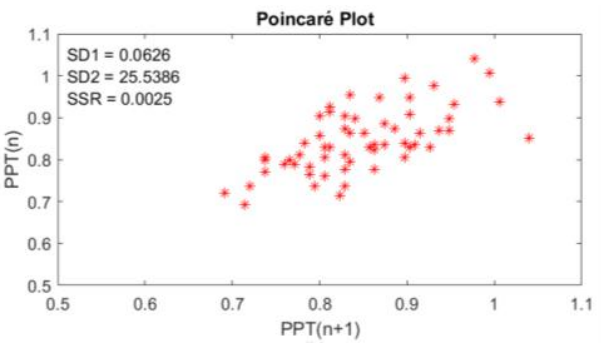

(b)

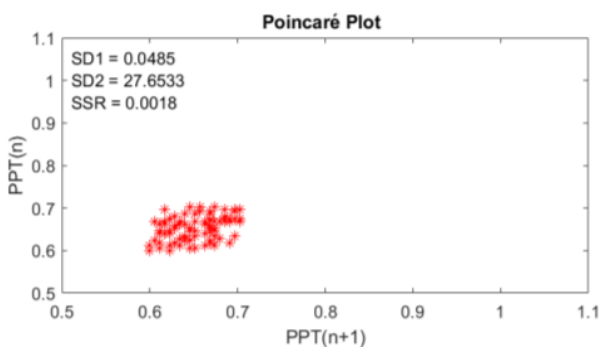

(d)

Figure 2. Raw PPG signal of (a) a non-smoker, (b) Poincaré plot of PPG signal from a non-smoker, (c) smoker, and (d) Poincaré plot of PPG signal from a smoker.

\subsection{Correlation of SD1, SD2, and SSR between non-smokers and smokers}

The two essential parameters of Poincaré method are SD1 (relates to short term variations of PRV) and SD2 (corresponds to long term variations of PRV). SD1 was significantly lower in smoker participants than that in their non-smoker counterpart as shown in Table 2. This results are more accurate than another similar work [19]. The difference between two groups might be related to nicotine in cigarette. Nicotine stimulates adrenaline secretion, while adrenalin stimulates the work of the heart and vasoconstriction of blood vessels. Smoker has more nicotine than non-smoker, therefore it could be influence in the blood circulation. On the other hand, the SD2 of non-smokers is lower than smokers due to correspond to the reduction of arterial function. Smoking is one of the prospective causes in buildup of fatty substances in the blood vessel. Plaque in the walls of the blood vessel might resist the blood flow through the arteries. As a result, supply blood to the heart become decline of oxygen-rich blood to the heart, especially during the time of increased activity. A heart dysfunction or injury to the heart muscle will be occurred when the coronary arteries are completely blocked.

Table 2. Relationship of SD1, SD2, and SSR between non-smokers and smokers

\begin{tabular}{cccc}
\hline \multirow{2}{*}{ Parameters } & \multicolumn{2}{c}{ Groups (mean \pm SD) } & \multirow{2}{*}{ p-value } \\
& Non-smokers & smokers & \\
\hline SD1 & $0.06 \pm 0.03^{*}$ & $0.03 \pm 0.01$ & 0.024 \\
SD2 & $25.7 \pm 0.5^{* *}$ & $27.33 \pm 0.36$ & 0.000 \\
SSR & $0.0023 \pm 0.0012^{*}$ & $0.0012 \pm 0.0005$ & 0.015 \\
\hline
\end{tabular}

\section{CONCLUSION}

The three parameters of Poincaré plots exert good performances to significantly differentiate the PPG signals of the non-smoker's group from those of smokers. We revealed that the parameters of Poincaré plots including SD1, SD2, and SSR exert good performances to significantly differentiate the PPG signals of the group of non-smokers from those of smokers. We also suppose that the method promises to be a suitable method to distinguish the cardiovascular disease group, especially to detect the blood circulation status between non-smoking and smoking subjects. Therefore, this method can be applied as a part of early detection system of CVDs. 


\section{ACKNOWLEDGEMENTS}

Special thanks to the student's research group at the Department of Pharmacology and Clinical

Pharmacy, Universitas Ahmad Dahlan for helping with the data collection.

\section{REFERENCES}

[1] G. M. Lin, B. Haryadi, C. M. Yang, S. C. Chu, C. C. Yang, and H. T. Wu, "Discrepancies between conventional multiscale entropy and modified short-time multiscale entropy of photoplethysmographic pulse signals in middle- and old-aged individuals with or without diabetes," Entropy, vol. 19, no. 3, Mar. 2017, Art. no. 132, doi: 10.3390/e19030132.

[2] B. Haryadi, J. J. Liou, H. C. Wei, M. X. Xiao, H. T. Wu, and C. K. Sun, “Application of multiscale Poincaré short-time computation versus multiscale entropy in analyzing fingertip photoplethysmogram amplitudes to differentiate diabetic from non-diabetic subjects," Comput. Methods Programs Biomed., vol. 166, pp. 115-121, Nov. 2018, doi: 10.1016/j.cmpb.2018.10.001.

[3] Y. K. Qawqzeh, A. S. Bajahzar, M. Jemmali, M. M. Otoom, and A. Thaljaoui, "Classification of Diabetes Using Photoplethysmogram (PPG) Waveform Analysis: Logistic Regression Modeling," Biomed Res. Int., vol. 2020, pp. 1-6, Aug. 2020, doi: 10.1155/2020/3764653.

[4] T. Aydemir, M. Sahin, and O. Aydemir, "Determination of hypertension disease using chirp z-transform and statistical features of optimal band-pass filtered short-time photoplethysmography signals," Biomed. Phys. Eng. Express, vol. 6, no. 6, Nov. 2020, Art. no. 65033, doi: 10.1088/2057-1976/abc634.

[5] C. T. Yen, S. N. Chang, and C. H. Liao, "Deep learning algorithm evaluation of hypertension classification in less photoplethysmography signals conditions," Meas. Control (United Kingdom), vol. 54, no. 3-4, pp. 439-445, Mar. 2021, doi: $10.1177 / 00202940211001904$

[6] Y. Liang, Z. Chen, R. Ward, and M. Elgendi, "Hypertension assessment using photoplethysmography: A risk stratification approach," J. Clin. Med., vol. 8, no. 1, Art. no. 12, Dec. 2019, doi: 10.3390/jcm8010012.

[7] Y.K. Qawqzeh, M. Reaz, M. A. M. Ali, and O. Maskon, "Photoplethysmography analysis of artery properties in patients presenting with established erectile dysfunction," in ICECT 2010 - Proceedings of the 2010 2nd International Conference on Electronic Computer Technology, 2010, pp. 165-168, doi: 10.1109/ICECTECH.2010.5480006.

[8] Y. K. Qawqzeh, "The analysis of PPG time indices to predict aging and atherosclerosis," in Learning and Analytics in Intelligent Systems, Springer International Publishing, 2020, pp. 218-225.

[9] R. Banerjee, A. D. Choudhury, R. Vempada, A. Pal, and K. M. Mandana, "Identifying coronary artery disease from photoplethysmogram," in UbiComp 2016 Adjunct - Proceedings of the 2016 ACM International Joint Conference on Pervasive and Ubiquitous Computing, Sep. 2016, pp. 1084-1088, doi: 10.1145/2968219.2972712.

[10] N. Paradkar and S. Roy Chowdhury, "Coronary artery disease detection using photoplethysmography," in Proceedings of the Annual International Conference of the IEEE Engineering in Medicine and Biology Society, EMBS, Jul. 2017, pp. 100-103, doi: 10.1109/EMBC.2017.8036772.

[11] T. Saritas et al., "Non-invasive evaluation of coronary heart disease in patients with chronic kidney disease using photoplethysmography," Clin. Kidney J., vol. 12, no. 4, pp. 538-545, Jan. 2019, doi: 10.1093/ckj/sfy135.

[12] N. Saquib, M. T. I. Papon, I. Ahmad, and A. Rahman, "Measurement of heart rate using photoplethysmography," Jan. 2015, doi: 10.1109/NSysS.2015.7043525.

[13] B. Askarian, K. Jung, and J. W. Chong, "Monitoring of heart rate from photoplethysmographic signals using a Samsung Galaxy Note8 in underwater environments," Sensors (Switzerland), vol. 19, no. 13, Jun. 2019, Art. no. 2846, doi: 10.3390/s19132846.

[14] X. Yu, T. Laurentius, C. Bollheimer, S. Leonhardt, and C. H. Antink, "Noncontact Monitoring of Heart Rate and Heart Rate Variability in Geriatric Patients Using Photoplethysmography Imaging," IEEE J. Biomed. Heal. Informatics, vol. 25, no. 5, pp. 1781-1792, May 2021, doi: 10.1109/JBHI.2020.3018394.

[15] Q. Zhang, D. Zhou, and X. Zeng, "Highly wearable cuff-less blood pressure and heart rate monitoring with single-arm electrocardiogram and photoplethysmogram signals," Biomed. Eng. Online, vol. 16, no. 1, Feb. 2017, doi: 10.1186/s12938-0170317-z.

[16] M. A. Islam and M. Ahmad, "Design and implementation of non-invasive continuous blood pressure measurement and monitoring system using photoplethysmography," in ICECE 2018 - 10th International Conference on Electrical and Computer Engineering, Dec. 2019, pp. 173-176, doi: 10.1109/ICECE.2018.8636725.

[17] C. J. McAloon et al., "The changing face of cardiovascular disease 2000-2012: An analysis of the world health organisation global health estimates data," Int. J. Cardiol., vol. 224, pp. 256-264, Dec. 2016, doi: 10.1016/j.ijcard.2016.09.026.

[18] M. Khoramdad, A. Vahedian-azimi, L. Karimi, F. Rahimi-Bashar, H. Amini, and A. Sahebkar, "Association between passive smoking and cardiovascular disease: A systematic review and meta-analysis,” IUBMB Life, vol. 72, no. 4, pp. 677-686, Dec. 2020, doi: 10.1002/iub.2207.

[19] P. Shi, Y. Zhu, J. Allen, and S. Hu, "Analysis of pulse rate variability derived from photoplethysmography with the combination of lagged Poincaré plots and spectral characteristics," Med. Eng. Phys., vol. 31, no. 7, pp. 866-871, Sep. 2009, doi: 10.1016/j.medengphy.2009.05.001.

[20] T. Hidayati, Akrom, Indrayanti, and Sagiran, "Evaluation of the black cumin seed oil role (BCSO) on a decline in eNOS expression and plasma NO levels: initial studies kemopreventive BCSO for lung cancer," Int. J. Biosci. Biochem. Bioinforma., vol. 7, no. 3, pp. 162-168, 2017, doi: 10.17706/ijbbb.2017.7.3.162-168

[21] K. H. Choi, J. Kim, O. S. Kwon, M. J. Kim, Y. H. Ryu, and J. E. Park, "Is heart rate variability (HRV) an adequate tool for evaluating human emotions? - A focus on the use of the International Affective Picture System (IAPS)," Psychiatry Res., vol. 251, pp. 192-196, May 2017, doi: 10.1016/j.psychres.2017.02.025.

[22] I. S. Riddervold et al., "Effects of wood smoke particles from wood-burning stoves on the respiratory health of atopic humans," Part. Fibre Toxicol., vol. 9, no. 1, Apr. 2012, doi: 10.1186/1743-8977-9-12.

[23] N. Selvaraj, A. Jaryal, J. Santhosh, K. K. Deepak, and S. Anand, "Assessment of heart rate variability derived from finger-tip photoplethysmography as compared to electrocardiography," J. Med. Eng. Technol., vol. 32, no. 6, pp. 479-484, Jan. 2008, doi: $10.1080 / 03091900701781317$.

[24] A. Schäfer and J. Vagedes, "How accurate is pulse rate variability as an estimate of heart rate variability?: A review on studies comparing photoplethysmographic technology with an electrocardiogram,” Int. J. Cardiol., vol. 166, no. 1, pp. 15-29, Jun. 2013, doi: 10.1016/j.ijcard.2012.03.119.

[25] S. Liu, J. Teng, X. Qi, S. Wei, and C. Liu, "Comparison between heart rate variability and pulse rate variability during different sleep stages for sleep apnea patients," Technol. Heal. Care, vol. 25, no. 3, pp. 435-445, Jun. 2017, doi: 10.3233/THC-161283. 
[26] A. K. Verma, P. N. Aarotale, P. Dehkordi, J. S. Lou, and K. Tavakolian, "Relationship between ischemic stroke and pulse rate variability as a surrogate of heart rate variability," Brain Sci., vol. 9, no. 7, Jul. 2019, Art. no. 162, doi: 10.3390/brainsci9070162.

\section{BIOGRAPHIES OF AUTHORS}

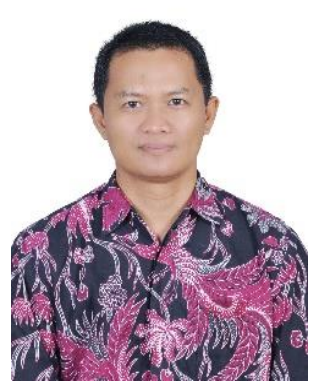

Bagus Haryadi (iD $8 \mathrm{SC}$ P was born in Sleman, Indonesia, on February 18, 1976. He received the BS degree in Physics Department in 2002 from Universitas Ahmad Dahlan, Indonesia, and the MS degrees in Instrumentation and Control in 2007 from Insitut Teknologi Bandung, Indonesia. Since September 2016, he has been a PhD student in the Department of Electrical Engineering, National Dong Hwa University, Hualien, Taiwan. His research interests include instrumentation, digital signal processing, and biomedical engineering. $\mathrm{He}$ can be contacted at email: bagus.haryadi@ fisika.uad.ac.id.

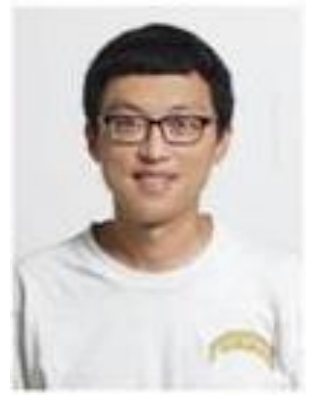

Po-Hao Chang (iD 81 SC P was born in Taipei, Taiwan, on September 5, 1966. He received the BS degree in Electrical Engineering in 1989 from National Taiwan University, Taiwan, and the MS and the PhD degrees in Electrical and Computer Engineering, in 1993 and 2000, respectively, from Purdue University, West Lafayette, Indiana, USA. Since August, 2000, he has been an assistant professor in the Department of Electrical Engineering, National Dong Hwa University, Hualien, Taiwan. His research interests include communication theories, digital communications, wireless and optical communications, and biomedical engineering. He can be contacted at email: po@gms.ndhu.edu.tw.

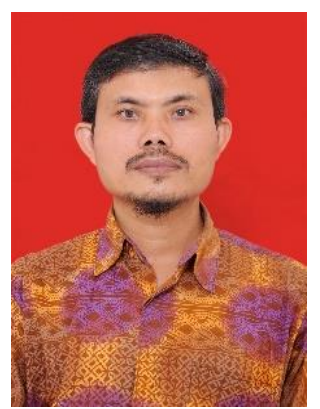

Akrom (D) 8d SC P He received the BS degree in Medical Doctor Department in 1998 from Universitas Gadjah Mada, Indonesia, and the MS and $\mathrm{PhD}$ degrees in Pharmacoimmulogy from Universitas Gadjah Mada, Indonesia, in 2004 and 2013, respectively. He has been a lecturer in the Department of Pharmacology and Clinical Pharmacy, Universitas Ahmad Dahlan, Indonesia. His research interests include pharmacoimmulogy and clinical pharmacy. He can be contacted at email: akrom@pharm.uad.ac.id.

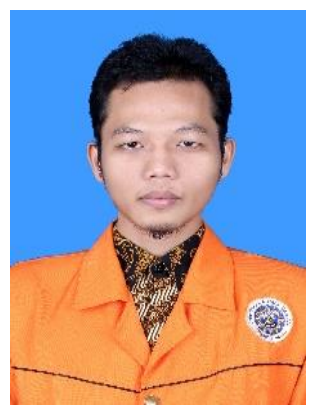

Arifan Q. Raharjo (D) SC SC was born in Bojonegoro, Indonesia, on November 28, 1996. He has been studying in Department of Physics, Universitas Ahmad Dahlan. His research interests include instrumentation and signal processing. He can be contacted at email: ifanharjo@gmail.com.

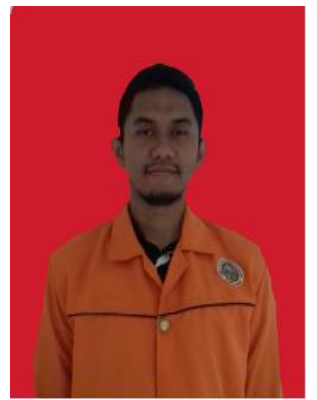

Galih Prakoso (iD 8d SC P was born in Bogor, Indonesia, on December 11, 1997. He has been studying in Department of Physics, Universitas Ahmad Dahlan. His research interests include instrumentation and signal processing. He can be contacted at email: galihgalih178@gmail.com. 